\title{
A língua mobilizada na conversação: princípios metodológicos para um trabalho de investigação
}

Marlete Sandra Diedrich*

Karina de Almeida Rigo**

\section{Resumo}

Este artigo tematiza o papel do pesquisador frente à particularidade da pesquisa na área da Linguística cujo foco de interesse seja a língua mobilizada na conversação. Trabalhos dessa natureza, em geral, se guiam por dois princípios básicos: a escolha de domínios autênticos, ou seja, a língua observada em sua realidade interacional cotidiana; e a complexidade da análise do material significante, que aponta para além do verbal. Neste artigo, cuja reflexão é resultado de pesquisas envolvendo a observação de situações conversacionais, tem-se o objetivo de, com enfoque nos desafios e nas potencialidades de tal realidade, refletir acerca do papel do pesquisador frente a esses dois princípios, os quais apontam para um trabalho de investigação que leve em conta, entre outros fatores, o contexto de produção dos materiais, a complexidade dos dados a serem registrados e a mobilização de recursos paraverbais na constituição do verbal.

Palavras-chave: Conversação. Interação. Papel do pesquisador.

\section{Introdução}

Faz-se necessário, primeiramente, definir o que entendemos por conversação e situar a área de estudos que dela tem se ocupado. Trabalhamos com o conceito de conversação apresentado por Marcuschi (1988, p. 319):

[...] interação centrada, da qual participam pelo menos dois interlocutores que se revezam, tomando cada qual pelo menos uma vez a palavra, dando-se o evento comunicativo em uma identidade temporal e num determinado "campo social”.

$\mathrm{Na}$ reflexão que trazemos aqui nos voltamos para o trabalho do pesquisador cujo interesse se estabelece na conversação como objeto de estudo. Por essa

Professora do Curso de Letras e do Programa de Pós-Graduação em Letras da Universidade de Passo Fundo. E-mail: marlete@upf.br

** Mestranda e bolsista Capes (Modalidade II) no Programa de Pós-Graduação em Letras da Universidade de Passo Fundo. E-mail: karinarigo@gmail.com

Data de submissão: set. 2017 - Data de aceite: out. 2017 http://dx.doi.org/10.5335/rdes.v13i3.7404 
razão, elegemos, a partir da leitura de referenciais não só da Análise da Conversação, mas de campos mais amplos, entendidos como parte da Linguística Interacional, dois princípios metodológicos que consideramos fundamentais nas pesquisas que temos realizado: a escolha de domínios autênticos, ou seja, a língua observada em sua realidade interacional cotidiana; e a complexidade da análise do material significante, que envolve os elementos verbais e paraverbais. Nosso objetivo é refletir acerca do papel do pesquisador frente a esses dois princípios, com enfoque nos desafios e potencialidades de tal realidade.

Sendo assim, organizamos este artigo da seguinte forma: iluminamos a questão situando os estudos da conversação no universo da Linguística; na sequência, discutimos os dois princípios metodológicos e suas implicações para o trabalho do pesquisador, para, por fim, apresentar suas potencialidades e limitações.

Ressaltamos, desde já, que as ideias aqui apresentadas não representam um consenso nas diversas linhas teóricas que se ocupam da conversação, mas são discutidos e analisados por praticamente todas elas, representando, em nossa experiência com a pesquisa, o resultado de um saber vivenciado e construído na prática de investigação de situações conversacionais tanto naturais como institucionais. Acerca disso, vale dizer que por naturais Marcuschi (2001) entende aquelas que se marcam por alto grau de espontaneidade, enquanto as institucio- nais se caracterizam por um grau menor de espontaneidade, como ocorre em consultas médicas ou em aulas ministradas por um professor. Trata-se, na verdade, de um continuum, no qual os diferentes tipos de conversação se revelam como

[...] atividade prática e cotidiana, cujo desenvolvimento depende da auto-organização patrocinada interacionalmente pelos interactantes (HILGERT, 1989, p. 82).

\section{A conversação como objeto de estudo da Linguística}

Entendemos ser importante trazermos aqui o percurso dos estudos da conversação no âmbito da Linguística para que possamos entender melhor a especificidade do objeto com o qual trabalhamos, o que justifica o destaque aos dois princípios metodológicos analisados.

No Brasil, os estudos sobre o texto falado têm um sólido percurso traçado. É sabido que projetos como o da Norma Urbana Culta (Nurc), que se iniciou na década de 1970, e o Projeto da Gramática do Português Falado, iniciado no final da década de 1980, originaram uma série de pesquisas e publicações que foram abrindo espaço no meio acadêmico brasileiro para o que se configura hoje como estudos do texto falado e, em meio a eles, os estudos da conversação. Mas é principalmente com os trabalhos de Luiz Antônio Marcuschi, com destaque para a publicação de Análise da Conversação, em 1986, que as pesquisas sobre 
conversação, no Brasil, começam a ser exploradas efetivamente.

Os estudos da conversação no Brasil têm se desenvolvido sob orientação de uma vertente denominada Análise da Conversação. A Análise da Conversação, segundo Kerbrat-Orecchioni (2006), ao olhar para a interação face a face, procura dar conta de um discurso que é inteiramente coproduzido, é o produto de um trabalho colaborativo incessante que ocupa o enfoque interacionista das produções linguísticas.

É necessário dizer que a Análise da Conversação liga-se, em sua origem, à Sociologia. Isso porque se inspira na Etnometodologia, a qual propõe uma nova postura investigativa e de apreensão da realidade social. A relevância teórica e epistemológica da Etnometodologia deve-se ao fato de realizar um rompimento com as linhas tradicionais da Sociologia, arraigada em estudos quantitativos e de larga escala. Ao priorizar as práticas ordinárias no aqui e agora localizado das interações, a Etnometodologia soma-se a outras correntes colocadas à margem da Sociologia vigente na época, a qual data do final da década de 1960 .

A corrente foi idealizada pelo sociólogo americano Harold Garfinkel. O termo etnometodologia foi cunhado pelo próprio Garfinkel e apresentado em seu livro fundador, Studies in Ethnomethodology (1967). Etimologicamente, portanto, tem-se etno/método/logia, ou seja: estudo (logos) dos métodos usados pelas pessoas (ethnos) em suas vidas cotidianas. De acordo com Watson e Gastaldo (2015), pode-se definir tal corrente como uma "abordagem naturalista das ciências sociais".

Os etnometodólogos entendem que a constituição da realidade social se realiza por seus membros de uma maneira estruturada, ordenada e metódica. Os atores sociais de uma sociedade dispõem de técnicas, de métodos - aqui, método tem um sentido pré-científico - próprios para organizar suas interações no cotidiano. Nesse sentido, a linguagem caracteriza-se como recurso para que os membros de uma sociedade possam dizer a realidade social: por meio da utilização da linguagem, a realidade social é descrita e constituída. Os etnometodólogos, portanto, denunciam que o olhar sociológico vigente na época não dá conta de "como os atores percebem e interpretam o mundo, reconhecem o familiar e constroem o aceitável, e não explica como as regras governam concretamente as interações" (COULON, 1995, p. 19).

Por mais que se possa perceber a relação estreita dessa corrente sociológica alternativa com a linguagem, faz-se necessário explicitar como se deu a transposição de suas concepções para a Linguística. A partir da década de 1970, a Etnometodologia ramifica-se em dois grandes grupos: o dos analistas de conversação e o dos sociólogos. Este se dirige aos objetos mais tradicionais sobre os quais a sociologia se debruça: a educação, a justiça, as organizações, as administrações, a ciência. Aquele prioriza nas conversas as reconstru- 
ções linguísticas que permitem lhes dar um sentido. Conforme estabelece Silva (2005, p. 41), "o que é conhecido como Análise da Conversação de linha etnometodológica surgiu, basicamente, a partir dos estudos de Harvey Sacks e seus colaboradores, com um enfoque em direção ao estudo da organização social da conduta cotidiana".

Em relação às particularidades da Análise da Conversação etnometodológica, Silva estabelece algumas considerações pertinentes:

A AC preocupa-se com a vinculação situacional e com o caráter pragmático da conversação. Essa contextualidade é reflexiva, pois o contexto de agora será, em princípio, o emulador do contexto seguinte. A contextualização é básica para que os ouvintes possam interpretar o que ouvem. Dessa maneira, os analistas da conversação recusam a construção de teorias prematuras e a idealização de materiais investigados, e por isso procedem a análises empíricas, mediante análises exaustivas dos fenômenos. Procuram, também, conhecer os procedimentos organizados tal qual aparecem na realidade (SILVA, 2005, p. 43).

É, precisamente, essa característica de observar a troca a partir do lugar, e no momento em que ela acontece, que faz com que a influência etnometodológica da Análise da Conversação se ajuste, sobremaneira, à investigação da linguagem sob forma de imersão no seio da situação real de troca. Diante dessa especificidade, voltemos, portanto, à extensão ao campo linguístico da Análise da Conversação. No Brasil, a Análise da Conversação foi introduzida por Marcuschi (1986) a partir de traba- lhos em Análise da Conversação de linha etnometodológica articulados a uma perspectiva mais linguística, a qual pretendia apreender as sistematicidades da língua e os reflexos dessas na interação.

Segundo Leite et al. (2010), a história da Análise da Conversação, em nível mundial, pode ser dividida em dois momentos. O primeiro, por volta dos anos 1970, em que o interesse se constituía na descrição dos mecanismos de organização da conversação e das relações intersubjetivas. Deste, herdaram-se os princípios de estudos dos turnos conversacionais (tomada, assunção, cessão ou perda da palavra em uma troca) e a concepção dos tipos de interação e das trocas simétricas ou assimétricas. $\mathrm{O}$ segundo momento deu vazão a um maior envolvimento dos pesquisadores com os procedimentos linguísticos específicos do texto falado.

Vale lembrar que a conversação não se limita a um tipo de texto, além disso, configura-se como uma organização de eventos linguísticos tipificáveis moldados de acordo com as formas de realizações em determinado cenário social. A Análise da Conversação se dedica a observar e descrever os fundamentos gerais que estruturam o texto falado e possibilita um avanço na análise quando concebe essa estrutura na esfera da construção do processo de interação entre falantes.

Portanto, diferentemente do viés epistemológico da Sociologia, a Análise da Conversação de viés linguístico não pretende se dedicar às relações entre grupos, classes ou instituições proje- 
tadas no discurso, e, sim, às relações intersubjetivas concretizadas por meio da conversação, como se verifica nas micronegociações, nas quais os interactantes são capazes de produzir enunciados adaptados à situação comunicativa e ao discurso do outro.

Contudo, não podemos deixar de considerar que, em nossas pesquisas, ao voltarmo-nos à concretização dessas relações via língua, vimo-nos diante de algumas âncoras estabelecidas pela Etnometodologia e que influenciam a escolha metodológica com a qual trabalhamos, destacando-se, entre elas, os princípios de escolha de domínios autênticos e a análise da complexidade do material significante mobilizado na conversação, o qual aponta para além do verbal, com inclusão dos elementos paraverbais.

Hoje, os estudos da conversação sofrem influência de diversos campos: sociólogos, psicólogos, antropólogos, linguistas, entre outros, somam esforços para, a partir do estudo da conversação, compreender mais sobre o próprio homem e suas relações sociais via linguagem. No âmbito da Linguística, ocupam-se da conversação os estudos específicos da Análise da Conversação, além de pesquisas desenvolvidas no âmbito da Análise do Discurso, da Linguística Textual, da Semiótica Discursiva, entre outros campos, o que favorece uma intense rede de saberes em torno do mesmo objeto.

\section{Os dois princípios básicos}

A partir do percurso apresentado na seção anterior, podemos perceber que os estudos da conversação foram sofrendo influências de diferentes campos, e, justamente por isso, entendemos ser importante esclarecer que nossas pesquisas se voltam para a vertente linguística influenciada pela Etnometodologia, o que nos leva a precisar determinados princípios a serem seguidos com vistas a contemplar o olhar do pesquisador da área da linguagem para os fatos advindos da conversação.

Kerbrat-Orecchioni (2007) nos motiva a essa reflexão, a partir de uma discussão acerca do estudo do discurso em interação, da qual derivamos nosso olhar para eleger a produção de materiais de pesquisa em contextos conversacionais autênticos e a análise da complexidade do material significante nesses contextos, o qual envolve elementos verbais e paraverbais, como princípios a serem analisados. Focalizemos, na sequência, cada um deles.

Em relação à necessidade de se trabalhar com a produção de materiais de pesquisa em contextos conversacionais autênticos, há de se lidar com a riqueza da inserção do pesquisador em tais contextos, mas também com os desafios e limites que uma inserção dessa natureza impõe ao trabalho.

Kerbrat-Orecchioni (2007) alerta para o fato de que, para conhecer as minúcias das interações cotidianas, o 
único meio confiável é o de registrar as trocas que se desenrolam entre pessoas reais, em situações reais. Para tanto, o pesquisador tem a opção de trabalhar com materiais já produzidos e que fazem parte de arquivos de pesquisa, usando as marcas discursivas e socio-históricas manifestadas no discurso para reconstruir as relações sociais mobilizadas na interação conversacional; ou de produzir seus próprios materiais de análise, o que exigirá dele a inserção direta nos contextos de produção. No caso de nossos trabalhos mais recentes, temos optado pela segunda possibilidade.

Nesse caso, o pesquisador vive o paradoxo de ser aceito nesses contextos, ao mesmo tempo em que deseja ter sua presença, se não ignorada nesse meio, ao menos, minimizada. $\mathrm{O}$ fato de ser aceito nas situações reais de comunicação envolve, entre outros, aspectos socioculturais, afetivos e éticos, os quais caracterizam o contexto da interação, em toda a sua complexidade de fatores: perfil dos interactantes, temas de cada conversação, entre outros. Certamente a presença física do pesquisador na situação de interação faz com que ele passe a ser também um interactante, estando apto a receber os olhares e as manifestações verbais dos demais envolvidos na conversação; no entanto, sua presença não pode influenciar por demais a situação e comprometer os dados. Trata-se de um limite traçado a partir de uma linha muito tênue, a qual só poderá ser devidamente delineada a partir de cada situação conversacional vivida, em toda a sua potencialidade de fato real de comunicação.

Além disso, há o fato de o pesquisador estar na situação conversacional, mas, muitas vezes, não ter todo o conhecimento prévio necessário para acompanhar a interação de forma plena. Isso porque, conforme afirma Kerbrat-Orecchioni (2007), comportamentos discursivos são, em grande parte, determinados pela relação socioinstitucional que existe entre os interlocutores: esses comportamentos podem certamente refletir na relação preexistente entre os interactantes e que nem sempre o analista consegue reconstituir por completo. No entanto, é importante frisar que a relação entre os interlocutores pode sempre ser modificada pelos próprios interlocutores. Trata-se de uma concepção dinâmica do contexto, a qual precisa ser levada em consideração, uma vez que ela tem papel decisivo no processo de produção e de interpretação do discurso. Para tanto, o pesquisador pode se valer de informações reveladas no contexto discursivo para chegar à análise do contexto macro em que o discurso foi produzido, posição assumida por grande parte dos pesquisadores que se voltam para o trabalho com a conversação; ou o pesquisador se volta para o contexto externo, o qual, segundo a autora, é de natureza heterogênea em relação ao texto, uma vez que compreende diferentes ingredientes: quadro espaço-temporal, natureza do canal, participantes, propósito da troca. 
Também neste caso ele está sujeito a uma remodelação incessante no curso do desenrolar da interação.

Em qualquer uma das escolhas de posição, o pesquisador se vê frente ao que podemos chamar de imprevisibilidade pragmática, dada a dinamicidade do evento comunicativo, a qual leva os interactantes a escolhas sempre renovadas no decorrer da conversação. Por essa razão, a conversação precisa sempre ser vista em sua dinamicidade de produção, como um processo e não como produto.

Vencido o desafio inicial da inserção e do tratamento do contexto, há de se dar conta de um registro adequado dos materiais produzidos, o que envolve conhecimento técnico sobre a captação e a edição de materiais audiovisuais. Em nossa experiência, temos analisado as potencialidades de uso do software Eudico Language Annotator (ELAN) ${ }^{1}$, denominação usada para identificar um recurso tecnológico desenvolvido pelo Instituto de Psicolinguística Max Planck, na Holanda, que permite a criação, edição, visualização e busca de anotações por meio de dados de vídeo e áudio.

A escolha por esse software se deve a várias razões. Entre elas, está a experiência bastante positiva construída em Diedrich (2015), com a análise dos fatos enunciativos na experiência de aquisição da linguagem pela criança, trabalho que envolve princípios teórico-metodológicos diferentes dos que nos movem na análise de conversações, mas que encontra identificação na produção de materiais de análise a partir de situações reais de comunicação. Nesse caso, o uso do Elan enriqueceu sobremaneira as possibilidades de interpretação dos materiais produzidos. Isso porque o recurso audiovisual que ele oferece permite que o pesquisador recupere, ao menos em parte, a produção do texto conversacional, no momento de sua análise. Outra possibilidade bastante produtiva na análise é o fato de podermos trabalhar com a inserção de trilhas na transcrição. Assim, ao inserir trilhas de comentários sobre a gestualidade dos interactantes, os olhares e entonações, o pesquisador consegue um quadro de elementos significantes muito mais complexo a ser levado em conta em suas análises do que aquele obtido a partir do material verbal tão somente. Tais comentários se mostram relevantes, uma vez que entendemos a transcrição como uma etapa de interpretação dos dados, conforme apresentamos em Diedrich:

Paradoxalmente, sabemos que uma experiência na linguagem não poderá jamais ser registrada por completo, pois ela extrapola o âmbito do registro e se constitui na efemeridade do aqui e do agora de cada enunciação. Além disso, a atividade de transcrição, sem dúvida, é altamente influenciada pelo olhar interpretativo do transcritor sobre o fato a ser transcrito, uma vez que esta etapa da investigação leva o pesquisador a uma tomada de decisões frente aos fatos (DIEDRICH, 2017, p. 215).

No caso do trabalho com a conversação, essa tomada de decisões é muito complexa, uma vez que há a necessidade de se ter o máximo de fidelidade possível 
às evidências linguísticas gravadas, o que leva o pesquisador a um exaustivo trabalho de audição e acompanhamento das cenas gravadas, num verdadeiro ir e vir constante aos registros efetuados, o que entendemos como a interrogação dos dados característica de pesquisas dessa natureza.

Não menos complexa, e intimamente relacionado a esse primeiro princípio, é a vivência, pelo pesquisador, do segundo princípio apontado neste artigo: a análise da complexidade do material significante nesses contextos. Nas interações conversacionais, concorrem para o estabelecimento do sentido muitos recursos além do verbal. Kerbrat-Orecchioni (1986) afirma que a comunicação é multicanal e pluridimensional, já que se compõe de significantes verbais, mas também de entonações, de risos e silêncios, de gestos, posturas, etc. A autora insere os elementos paraverbais na conversação compreendendo-os num universo geral de elementos significantes: os signos mobilizados na conversação podem ser do tipo linguísticos e não linguísticos. Entre os linguísticos, encontram-se os verbais, os quais envolvem o léxico e a sintaxe; e os vocais ou prosódicos, como as entonações, os acentos, as pausas, os quais, juntamente com os não linguísticos, compõem o grupo dos signos paraverbais. Entre os não linguísticos, encontram-se os elementos corporais visuais, estáticos e cinestésicos, como o olhar, os gestos, entre outros. $\mathrm{Ou}$ seja, são considerados pela autora como paraverbais os elementos chamados de vocais ou prosódicos e os não linguísticos, o que, certamente, representa um universo grande e de variados elementos, conforme ilustra o Quadro 1:

Quadro 1 - Elementos constitutivos do material significante segundo Kerbrat-Orecchioni

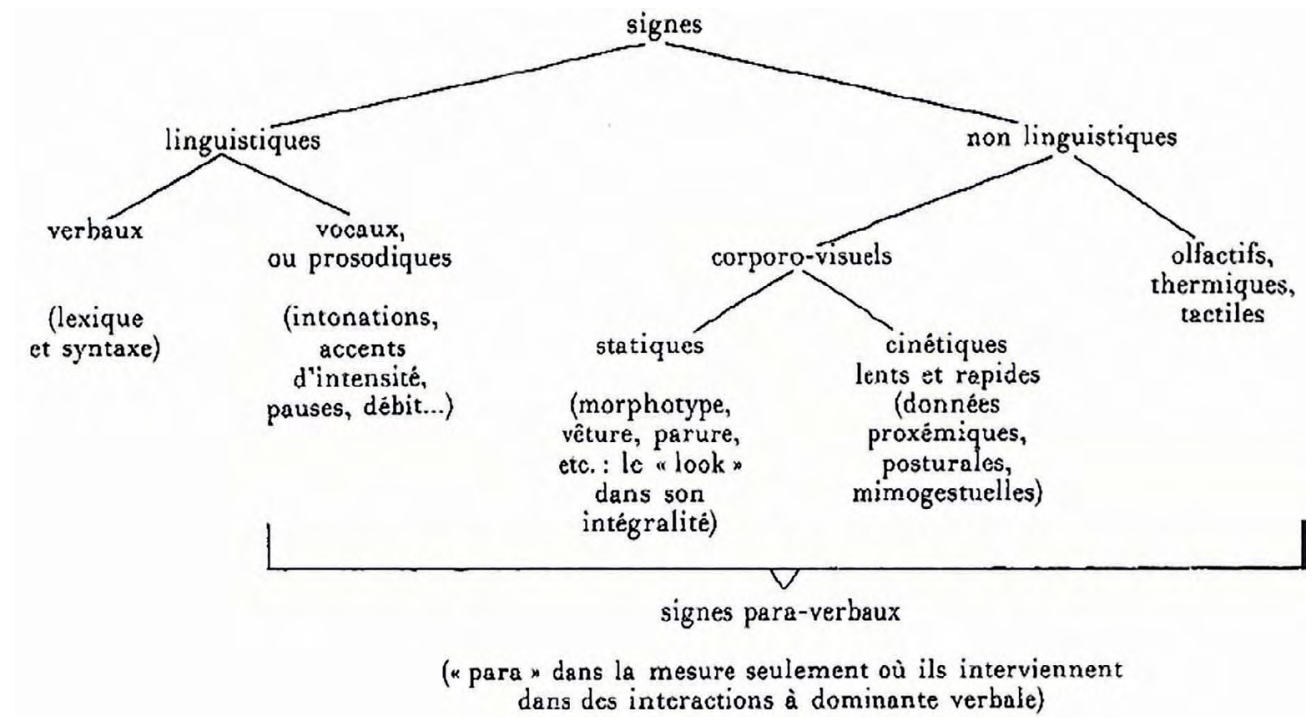

Fonte: Kerbrat-Orecchioni (1986). 
Sem dúvida, na conversação, elementos paraverbais desempenham um papel particularmente importante, uma vez que certos comportamentos são considerados como condição de possibilidade de interação, como a instauração, a continuidade ou o fechamento da interação conversacional, como é o caso dos proxêmicos, uma vez que a distância entre os interactantes pode ser decisiva para a qualidade da interação, mas principalmente, quanto à natureza particular de sua relação socioafetiva. A postura, a direção do olhar, por exemplo, podem estabelecer e manter o contato social, já que um gesto ou uma expressão facial pode constituir em si uma intervenção. Também os fatos prosódicos fornecem informações preciosas sobre a natureza da relação afetiva, entre outros.

Consideramos extremamente profícua a discussão em torno dos elementos paraverbais na pesquisa em conversação, uma vez que entendemos a ação desses elementos como uma espécie de roupagem dos elementos verbais, sendo, portanto, deles constitutivos e afetando-lhes o sentido. Acerca disso, lembramos da preocupação, já em 1974, de Hudinilson Urbano, quando, em texto ensaístico sobre elementos para o estudo da Pará linguística, afirma que:

os elementos paralingüísticos quebram o rigor da linearidade da linguagem, à medida que participam simultânea ou harmonicamente do significante como roupagem, ora despercebida, ora altamente expressiva, porém, sempre necessária (1974, p. 108).
Consideramos a ideia de roupagem extremamente feliz, uma vez que os elementos paraverbais afetam os elementos linguísticos verbais numa relação que não se dá num determinado nível linguístico, uma vez que esse elementos paraverbais não satisfazem o critério da dupla articulação da linguagem e, portanto, acabam por revestir os elementos que se deixam decompor na linearidade sígnica de forma a lhes afetar o sentido, o que nos leva a entendê-los como constitutivos do dizer.

Dada essa dimensão do material significante mobilizado nas conversações, faz-se necessário que o pesquisador busque estratégias de produção, registro e análise dos materiais conversacionais que deem conta de tal complexidade sígnica. Entre essas estratégias, já sugerimos o uso do Elan como recurso tecnológico para tratamento dos materiais, pois seu uso alcança tanto os elementos sonoros quanto visuais. No entanto, entendemos que a questão posta em análise aqui é mais ampla: pensamos na postura do pesquisador frente a esses materiais e a concepção de língua com a qual ele trabalha, a qual precisa abarcar os elementos paraverbais como elementos que afetam a língua, em suas formas e sentidos mobilizados na interação conversacional. 


\section{A experiência construída - desafios e potencialidades}

Apresentamos aqui, portanto, um olhar e uma tomada de postura metodológica que representa o resultado de uma experiência construída no universo da pesquisa com a conversação em contextos reais de interação. Nessa experiência, temos nos voltado para interações institucionalizadas, como é o caso da conversação desenvolvida entre professor e estudantes em uma sala de aula, mas também nos voltamos para conversações mais espontâneas, como são aquelas existentes entre crianças de dois a três anos. Em ambos os casos, deparamo-nos com a necessidade de refletir acerca dos dois aspectos discutidos neste artigo, uma vez que os entendemos como determinantes do nosso agir como pesquisadores nos contextos em questão.

Sabemos que, ao trabalhar com a língua mobilizada na conversação, não teremos condições de analisar a totalidade de recursos que lhe são constitutivos, assim como também não vemos possibilidade de uma reconstrução fiel e completa do contexto de interação propriamente dito, pois esse, em última instância, não é totalmente acessível ao analista, o qual acessa a projeção do contexto na conversação na busca de reconstruí-lo. $\mathrm{O}$ observador insere-se no ambiente em que se desenrola uma situação concreta de troca interacional, a fim de registrar uma parcela do que consegue capturar, já que o todo é - e sempre será - inalcançável. A partir do registro e de sua memória, os fatos a serem analisados se materializam. Desse "dado" imprevisível a priori, e somente com base nele, o método delineia-se de forma a permitir que as perguntas sejam iluminadas pela reflexão teórica.

Dada a imprevisibilidade dos fatos de linguagem observados na conversação, há a atualização constante das perguntas da pesquisa. Esse mover científico, não linear no percurso da pesquisa, representa para nós uma das grandes potencialidades dos trabalhos de pesquisa na área da conversação, pois se apresenta ao pesquisador sempre como um desafio renovado, exigindo dele um olhar muito particular para o fenômeno interacional que tem a descrever e a explicar.

Como resultado dessa complexa rede de mobilização de saberes e renovação de olhares, fica a certeza de que a pesquisa na área da linguagem será sempre limitada, já que temos plena consciência do que afirma Teixeira (2012, p. 71): “o ato de linguagem comporta um enigma que não tem como ser totalmente decifrado". Trabalhamos, portanto, com um olhar sempre frente ao fenômeno amplo e complexo que é a linguagem. 


\section{The language mobilized in the conversation: methodological principles for a research effort}

\begin{abstract}
This article discusses the role of the researcher in relation to the particularity of the research in the field of Linguistics whose focus of interest is the language mobilized in the conversation. Surveys of this nature are, generally, guided by two basic principles: the choice of authentic domains, that is, the language observed in their everyday interactional reality; and the complexity of the analysis of the significant material, which points beyond the verbal. In this article, whose reflection is the result of studies involving the observation of conversational situations, the objective is to reflect on the researcher's role on these two principles, focusing on the challenges and potentialities of such reality, which point to a research effort that takes into account, among other factors, the context of material production, the complexity of the data to be recorded and the mobilization of paraverbal resources in the constitution of the verbal.
\end{abstract}

Keywords: Conversation. Interaction. Researcher's role.

\section{Nota}

1 O software livre pode ser obtido em: <https:// tla.mpi.nl/tools/tla-tools/elan/>.

\section{Referências}

COULON, Alain. Etnometodologia e educação. Petrópolis, RJ: Vozes, 1995.

DIEDRICH, Marlete Sandra. Aquisição da linguagem: o aspecto vocal da enunciação na experiência da criança na linguagem. Tese (Doutorado em Letras - Estudos da Linguagem/Teorias do Texto e do Discurso) - Instituto de Letras, Universidade Federal do Rio Grande do Sul, Porto Alegre, 2015. Disponível em: <http://hdl.handle. net/10183/130026 >. Acesso em: 23 jun. 2017.

. Os registros da experiência da criança na linguagem: $o$ ato enunciativo de transcrição. Revista Estudos da Linguagem, Belo Horizonte, v. 25, n. 2, p. 711-737, 2017. Disponível em: <http://www.periodicos.letras. ufmg.br/index.php/relin/article/view/10587>. Acesso em: 23 jul. 2017.

HILGERT, José Gaston. A paráfrase: um procedimento de constituição do diálogo. Tese (Doutorado em Letras - Filologia e Língua Portuguesa) - Faculdade de Filosofia e Ciência, Universidade de São Paulo, São Paulo, 1989.

KERBRAT-ORECCHIONI, Catherine. "Nouvelle communication "et "analyse conversationnelle”. In: Langue Française, n. 70, 1986. Communication et enseignement. p. 7-25.

. Análise da conversação: princípios e métodos. Tradução de Carlos Piovezani Filho. São Paulo: Parábola, 2006.

L'analyse du discours en interaction: quelques principes méthodologiques. Limbaje si comunicare, IX, p. 13-32, 2007.

LEITE, Marli Quadros et al. A análise da conversação no Grupo de Trabalho Linguística do Texto e Análise da Conversação da Associação Nacional de Pós-Graduação em Letras e Linguística. In: BENTES, Anna Christina; LEITE, Marli Quadros (Org.). Linguistica de texto e análise da conversação. São Paulo: Cortez, 2010. p. 49-87. 
MARCUSCHI, Luiz Antônio. Análise da conversação. São Paulo: Ática, 1986.

Questões atuais na análise da conversação. In: ENCONTRO NACIONAL DA ANPOLL, 3. Recife: Anpoll, 1988. p. 319-335.

Da fala para a escrita: atividades de retextualização. São Paulo: Cortez, 2001.

SILVA, Luiz Antônio da. Conversação: modelos de análise. In: SILVA, Luiz Antônio da (Org.). A língua que falamos: Português: história, variação e discurso. São Paulo: Globo, 2005. p. 31-69.

TEIXEIRA, Marlene. O estudo dos pronomes em Benveniste e o projeto de uma ciência geral do homem. Desenredo, Passo Fundo, v. 8, n. 1, p. 71-83, jan./jun. 2012.

URBANO, Hudinilson. Margem de "À margem da dupla articulação"

de Martinet: elementos para um estudo de paralingüística. Língua e Literatura - USP, São Paulo, a. II, v. III, 1974.

WATSON, Rod; GASTALDO, Édison. $E t$ nometodologia e análise da conversa. Petrópolis, RJ: Vozes; Rio de Janeiro: Editora PUC-Rio, 2015. 